\title{
ANALISIS MANAJEMEN PERSEDIAAN BAHAN BAKU ROCKWOOL PADA USAHA HIDROPONIK (Studi Kasus di Nabila Farm, Desa Cibogo, Kecamatan Lembang, Kabupaten Bandung Barat)
}

\author{
ANALYSIS MANAGEMENT OF RAW MATERIAL INVENTORY OF ROCKWOOL \\ IN THE HYDROPONIC BUSINESS \\ (Case Study in Nabila Farm, Cibogo Village, Lembang District, \\ West Bandung Regency)
}

\author{
Karin Nafia Pramesti*, Sulistyodewi Nur Wiyono, Tuti Karyani, Pandi Pardian \\ Program Studi Agribisnis, Fakultas Pertanian, Universitas Padjadjaran \\ *Email: karin.pramesti26@gmail.com \\ (Diterima 15-04-2020; Disetujui 17-06-2020)
}

\begin{abstract}
ABSTRAK
Persediaan menjadi bagian terpenting pada setiap perusahaan, tidak terkecuali pada perusahaan hidroponik. Tujuan dari penelitian ini untuk menganalisis tingkat persediaan bahan baku rockwool yang optimal agar meminimalisir total biaya persediaan. Rockwool merupakan bahan baku penting yang dibutuhkan pada saat persemaian benih. Penelitian dilaksanakan pada bulan Oktober 2019 - Desember 2019 berlokasi di Nabila Farm, Desa Cibogo, Kecamatan Lembang, Kabupaten Bandung Barat. Data yang digunakan adalah data primer dan data sekunder. Penelitian dilakukan dengan teknik wawancara secara langsung dengan bagian koordinator farm dan juga menggunakan data tertulis dalam bentuk dokumen yang diperoleh dari perusahaan. Metode analisis data dengan menggunakan metode Economic Order Quantity (EOQ). Metode ini dapat menentukan kuantitas dan frekuensi pemesanan bahan baku rockwool yang optimal sehingga biaya persediaan bahan baku lebih efisien. Berdasarkan hasil perhitungan diperoleh bahwa pembelian bahan baku rockwool menurut metode EOQ pada saat periode November 2018 - Oktober 2019 lebih besar daripada kebijakan perusahaan dan kuantitas pembelian bahan baku rockwool optimal periode November 2018 - Oktober 2019 sebesar 90 bal dengan frekuensi pembelian 2 kali. Total biaya persediaan bahan baku rockwool di periode yang sama menurut metode EOQ lebih kecil daripada kebijakan perusahaan dan total biaya menurut metode EOQ sebesar Rp 889.946,11. Dari hasil penelitian yang telah dilakukan diperoleh bahwa manajemen persediaan bahan baku rockwool di Nabila Farm selama periode November 2018 - Oktober 2019 belum efisien.
\end{abstract}

Kata kunci: hidroponik, persediaan, bahan baku, EOQ

\begin{abstract}
Inventories are the most important part in every company, not least in hydroponics companies. The purpose of this study is to analyze the optimal inventory level of rockwool raw materials in order to minimize the total inventory cost. Rockwool is an important raw material needed when seeding. The study was conducted in October 2019 - December 2019 located at Nabila Farm, Cibogo Village, Lembang District, West Bandung Regency. The data used are primary data and secondary data. This research was conducted using direct interview techniques with the farm coordinator and also using written data in the form of documents obtained from the company. The data analysis method uses the Economic Order Quantity (EOQ) method. This method can determine the quantity and frequency of ordering optimal rockwool raw materials so that the cost of raw material inventory is more efficient. Based on the calculation results obtained that the purchase of rockwool raw materials according to the EOQ method during the period November 2018 - October 2019 is greater than the company policy and the optimal quantity of rockwool raw material purchases for the November 2018 - October 2019 period is 90 bales
\end{abstract}


with a frequency of purchase of 2 times. The total cost of rockwool raw material inventory in the same period according to the EOQ method is smaller than the company policy and the total cost according to the EOQ method is $R p$. 889,946.11. From the results of research that has been done, it is obtained that the management of raw material inventory of rockwool at Nabila Farm during the period November 2018 - October 2019 is inefficient.

Keywords: hydroponics, inventory, raw material, EOQ

\section{PENDAHULUAN}

Indonesia merupakan salah satu negara agraris yang masih berkembang. Oleh karena itu, pertanian merupakan sektor penting dalam membangun Indonesia, mulai dari perekonomian nasional, kebutuhan pangan masyarat, hingga perlengkapan industri. Pertanian terdiri atas beberapa subsektor, yaitu tanaman pangan, hortikultura, peternakan, perikan dan perkebunan. Perkembangan Pendapatan Domestik Bruto (PDB) untuk sub sektor hortikultura pada tahun 2014-2018 mengalami peningkatan, peningkatan tertinggi pada tahun 2018 sebesar 145.133 Miliar Rupiah (Badan Pusat Statistik, 2019). Komoditas hortikultura cukup potensial untuk dikembangkan secara agribisnis, karena memiliki nilai ekonomis dan nilai tambah yang cukup tinggi dibandingkan dengan komoditas lainnya (Martawijaya dan Nurjayadi, 2010).

Sayuran termasuk produk pertanian yang mendapatkan permintaan cukup tinggi dari segi jumlah maupun kualitas, seperti pada pasar swalayan, hotel, dan restoran atau pasar tradisional pada umumnya. Sayuran adalah jenis bahan makanan yang dikonsumsi oleh masyarakat untuk memenuhi kebutuhan pangan, vitamin, mineral serta gizi (Direktorat Jenderal Bina Hortikultura, 2001). Setiap tahun konsumsi sayuran per kapita nasional mengalami peningkatan. Dapat dilihat total produksi sayuran pada Tabel 1 .

Tabel 1. Produksi Hortikultura Tahun 2012-2016

\begin{tabular}{|c|c|c|c|c|c|c|}
\hline Komoditas & 2012 & 2013 & 2014 & 2015 & 2016 & $\begin{array}{c}\text { Laju } \\
\text { Pertumbuhan } \\
(\%)\end{array}$ \\
\hline Sayuran & 11.264 .972 & 11.558 .449 & 11.918 .414 & 11.629 .414 & 12.080 .269 & 3,88 \\
\hline $\begin{array}{l}\text { Buah- } \\
\text { Buahan }\end{array}$ & 18.916 .731 & 18.288 .279 & 19.805 .977 & 20.167 .376 & 18.341 .289 & $-9,05$ \\
\hline $\begin{array}{l}\text { Tanaman } \\
\text { Hias }\end{array}$ & 626.858 .625 & 684.097 .623 & 740.892 .371 & 785.166 .361 & 763.141 .773 & $-2,81$ \\
\hline $\begin{array}{l}\text { Tanaman } \\
\text { Biofarmaka }\end{array}$ & 374.656 .821 & 453.206 .124 & 484.025 .788 & 569.499 .438 & 585.272 .651 & 2,77 \\
\hline
\end{tabular}

Sumber: Badan Pusat Statistika dan Direktorat Jenderal Hortikultura, diolah 
Diantara beberapa provinsi di Indonesia yang mengusahakan budidaya hortikultura. Jawa Barat merupakan provinsi pertama dengan potensi yang cukup besar dalam mengembangkan budidaya hortikultura. Menururt data BPS, rata-rata produksi sayuran pada tahun 2014-2018 di Jawa Barat sebesar 11.309.753,44 ton. Salah satu daerah di Provinsi Jawa Barat yang menyumbang hasil sayuran tersebsar adalah Kabupaten Bandung Barat. Laju pertumbuhan produksi sayuran pada tahun 2017-2018 di Kabupaten Bandung Barat sebesar 60,24\%. Usaha untuk meningkatkan hasil produksi akan terus dilakukan karena permintaan sayuran yang terus meningkat dan peningkatan jumlah penduduk yang menyadari bahwa mengkonsumsi sayuran sangat bermanfaat untuk kesehatan.

Sayuran organik dan segar yang sedang sangat diminati adalah sayuran hidroponik. Pertumbuhan sayuran yang mencapai sekitas $20 \%$ per tahun adalah sebuah peluang bagi produsen sayuran hidroponik untuk memenuhi permintaan konsumen (Herwibowo dan Budiana, 2015). Hidroponik merupakan salah satu cara budidaya pertanian yang bisa digunakan dilahan yang sempit seperti perkotaan. Manfaat menggunakan budidaya hidroponik adalah produk pertanian yang berkualitas, higienis, bebas pestisida dan dapat dilakukan secara berkelanjutan. Sarana produksi yang diperlukan untuk teknik hidroponik diantaranya seperti, benih, rockwool, nutrisi, pot, dan lain-lain. Media tanam yang digunakan untuk hidroponik ada beberapa jenis diantaranya arang sekam, cocopeat, rockwool dan spons.

Media tanam yang sering digunakan untuk hidroponik adalah rockwool. Rockwool memiliki kelebihan yang tidak dimiliki oleh media tanam lainnya, terutama dalam komposisi air dan udara. Rockwool bersifat ramah lingkungan karena terbuat dari kombinasi bebatuan yang dipanaskan hingga meleleh yang kemudian akan berbentuk menjadi serat-serat. Rockwool memiliki serat yang banyak mempermudah penyerapan air, pupuk cair sekaligus udara yang membantu pertumbuhan akar dalam penyerapan unsur hara. Menggunakan rockwool sebagai media tanam telah terbukti aman, praktis, ekonomis dan hasil yang tinggi (Sonneveld, 1991).

Kecamatan Lembang salah satu yang mengembangkan pertanian khususny agribisnis sayuran karena memiliki jumlah produksi dan 
permintaan pasar cukup besar. Nabila Farm merupakan satu-satunya perusahaan yang membudidayakan sayuran secara hidroponik di Desa Cibogo. Nabila Farm yang menggunakan Green House untuk menanam sayuran secara hidroponik. Produk tanaman yang dihasilkan diantaranya kangkung, kailan, bayam merah, bayam hijau, kale, pakcoy, caisim dan baby kale. Nabila Farm memiliki kerjasama dengan mitra sehingga permintaan sayuran akan mengikuti permintaan mitra. Data penjualan di Nabila Farm dapat dilihat pada Tabel 2.

Tabel 2. Data Penjualan di Nabila Farm Bulan Mei-Agustus 2019

\begin{tabular}{lcccc}
\hline \multirow{2}{*}{ Jenis } & \multicolumn{4}{c}{ Satuan (Pack) } \\
\cline { 2 - 5 } \multicolumn{1}{c}{ Sayuran } & Mei & Juni & Juli & Agustus \\
\hline Bayam hijau & 1206 & 1180 & 805 & 1125 \\
Bayam merah & 733 & 1062 & 515 & 407 \\
Caisim & 1029 & 940 & 770 & 747 \\
Kailan & 942 & 843 & 521 & 995 \\
Kangkung & 50 & 90 & 116 & 185 \\
Pakcoy & 248 & 679 & 1333 & 530 \\
Pakcoy putih & 20 & 90 & 120 & 216 \\
Kale & 798 & 1272 & 1390 & 1265 \\
Petsai & 733 & 1062 & 515 & 407 \\
Baby kale & 1029 & 940 & 770 & 747 \\
\hline Sumber: Nabila Farm & & &
\end{tabular}

Tabel 2 menunjukan bahwa pada bulan Mei hingga Agustus mengalami fluktiatif, namun permintaan mitra mampu terpenuhi oleh Nabila Farm. Nabila Farm menggunakan rockwool sebagai media tanamnya. Permintaan mitra terus meningkat karena minat konsumen terhadap sayuran yang tinggi menyebabkan peningkatan pada proses persemaian dan perlu adanya perencanaan untuk memenuhi kebutuhan bahan baku rockwool. Total pemakaian rockwool di Nabila Farm dapat dilihat pada Tabel 3.

Tabel 3. Total Pemakaian Rockwool di Nabila Farm Bulan Mei-Agustus 2019

\begin{tabular}{clcccc}
\hline No & $\begin{array}{c}\text { Jenis } \\
\text { Sayuran }\end{array}$ & Mei & Juni & Juli & $\begin{array}{c}\text { Agus- } \\
\text { tus }\end{array}$ \\
\hline 1 & Bayam Hijau & 26 & 16 & 18,5 & 31 \\
2 & Bayam Merah & 25,5 & 22 & 18,5 & 33 \\
3 & Caisim & 16 & 7,5 & 17 & 6,5 \\
4 & Kailan & 16,5 & 6 & 12 & 6 \\
5 & Kangkung & 20 & 19 & 17 & 31 \\
6 & Pakcoy & 18 & 4,5 & 15,5 & 10,5 \\
7 & Pakcoy Putih & 3,5 & 2 & 3 & 2,5 \\
8 & Kale & 24 & 6 & 12 & 11,5 \\
9 & Petsai & 3,5 & 2 & 2,5 & 1 \\
\hline Total (Lembar) & 153 & 85 & 116 & 133 \\
\hline \multicolumn{7}{c}{ Total (Pack) } & 16 & 9 & 12 & 14 \\
\hline
\end{tabular}

Sumber: Nabila Farm

Peningkatan penggunaan rockwool terjadi pada bulan Mei hal ini terjadi karena permintaan di bulan Juni meningkat dan bertepatan pada Hari Raya Idul Fitri. Harga yang diperlukan untuk pembelian bahan baku rockwool pun cukup tinggi, untuk 1 pack rockwool seharga Rp 600.000,00,-. Nabila Farm belum bisa menentukan persediaan bahan baku rockwool yang tepat dan mengakibatkan beban biaya yang berlebih.

Masalah penentuan besarnya persediaan dalam usaha agribisnis akan mempengaruhi terhadap keuntungannya. Kesalahan dalam menentukan 
besarnya investasi (modal yang tertanam) dalam persediaan akan menekan keuntungan perusahaan (Murtiningsih, 2004). Pengendalian bahan baku yang tidak efisien akan menyebabkan biaya persediaan meningkat, keuntungan serta risiko terhadap kerusahan bahan juga semakin tinggi. Berdasarkan uraian tersebut, maka dapat dirumuskan masalah untuk penelitian sebagai berikut:

1. Bagaimana struktur biaya produksi usahatani Nabila Farm?

2. Bagaimana sistem persediaan bahan baku rockwool yang sedang berjalan di Nabila Farm Lembang?

3. Bagaimana mengoptimalkan persediaan bahan baku rockwool di Nabila Farm Lembang?

\section{METODE PENELITIAN}

Penelitian dilaksanakan di Nabila Farm yang berada di Desa Cibogo, Kecamatan Lembang, Kabupaten Bandung Barat. Pemelihan lokasi penelitian terkait dengan budidaya sayuran hidroponik. Budidaya hidroponik memerlukan rancangan usaha yang tepat, persiapan persediaan alat dan bahan baku yang perlu diperhatikan. Kebijakan pengendalian persediaan bahan baku yang tepat akan memenuhi kebutuhan proses produksinya. Nabila Farm perlu menerapkan kebijakan pengendalian persediaan bahan baku yang optimum dengan biaya yang minimum dapat tercapainya efisiensi biaya persediaan.

Desain penelitian yang digunakan adalah penelitian kualitatif dengan analisis kuantitatif. Penelitian kualitatif merupakan penelitian yang berkaitan dengan nilai atau makna dibalik fakta yang diungkapkan melalui bahasa atau kata-kata (Creswell, 2002). Teknik penelitian yang digunakan adalah dengan studi kasus. Sumber data yang digunakan dalam penelitian ini meliputi data primer dan data sekunder. Data primer adalah data yang didapatkan langsung dari sumber data sedangkan data sekunder adalah data yang sudah dikumpulkan dan dilaporkan. Teknik pengumpulan data dalam penelitian dengan wawancara ke lokasi penelitian, observasi, dan pencatatan data.

Analisis data yang digunakan adalah analisis biaya produksi, analisis usahatani, analisis biaya pemesanan bahan baku menururt kebijakan perusahaan dan analisis metode Economic Order Quantity (EOQ). Analisis biaya produksi dilakukan dengan menghitung komposisi biaya dari masing-masing komponen input usahatani. Adapun komposisi biaya 
tersebut ialah biaya tetap dan biaya variabel yang terdiri dari biaya peralatan produksi, biaya tenaga kerja dan penyusutan, juga biaya produksi seperti benih, pupuk, rockwool dan bahan bakar. Analisis Usahatani diperlukan perhitungan mengenai biaya produksi, penerimaan, dan keuntungan.

a. Total Biaya atau Total Cost (TC)

Total biaya adalah jumlah dari keseluruhan biaya yang dikeluarkan selama proses produksi. Total biaya didapat dari penjumlahan biaya tetap dan biaya variabel.

$\mathrm{TC}=\mathrm{FC}+\mathrm{VC}$

Keterangan:

$\mathrm{TC}=$ Total biaya $(\mathrm{Rp})$

$\mathrm{FC}=$ Biaya tetap $(\mathrm{Rp})$

$\mathrm{VC}=$ Biaya variabel $(\mathrm{Rp})$

b. Penerimaan Usahatani

Penerimaan adalah sejumlah uang yang diterima dari penjualan produknya kepada pedagang atau lansung kepada konsumen (Hussain, 2004). Penerimaan dihitung dengan rumus:

$\mathrm{TR}=\mathrm{P} \times \mathrm{Q}$

Keterangan:

$\mathrm{TR}=$ Penerimaan

$\mathrm{P} \quad=$ Harga jual produk

$\mathrm{Q}=$ Jumlah produksi

Dalam penelitian ini, penerimaan yang dimaksud adalah penerimaan dari penjualan produk sayuran. Penerimaan ini dihitung dari perkalian harga jual produk dan jumlah produksi dalam 1 tahun.

c. Keuntungan

Keuntungan adalah selisih antara total penerimaan dan jumlah seluruh biaya setelah dikenai pajak berlaku (Sukirno, 2000). Keuntungan usaha dapat dihitung dengan rumus:

Net Benefit $=(\mathrm{TR}-\mathrm{TC})$

Keterngan:

Net Benefit $=$ Keuntungan

TR $=$ Penerimaan

$\mathrm{TC}=$ Total biaya

Dalam penelitian ini, keuntungan bersih didapatkan dari selisih antara total penerimaan dan total biaya produksi setelah dikenai pajak penghasilan sebesar 25\% mengikuti Pasal 17 Ayat 1 Bagian b UU No. 36 Tahun 2008 tentang Pajak Penghasilan.

d. Return Cost of Ratio (RCR)

Return Cost of Ratio (RCR) adalah analisis yang digunakan untuk mengetahui efisiensi usahatani. Rumus yang digunakan untuk menghitung RCR yaitu (Hernanto, 1991):

$\mathrm{RCR}=\frac{\mathrm{TR}}{T C}$

Keterangan:

$\mathrm{RCR}=$ Ratio pengembalian biaya

$\mathrm{TR}=$ Total penerimaan

$\mathrm{TC}=$ Total biaya produksi 
Berdasarkan nilai tersebut, maka kriteria pengukurannya sebagai berikut:

a) Jika RCR $>1$, maka usahatani menguntungkan secara ekono-mis.

b) Jika $\mathrm{RCR}=1$, maka usahatani berada pada titik impas (break even point) yaitu keadaan dimana penerimaan sama dengan biaya total yang dikeluarkan.

c) Jika RCR $<1$, maka usahatani tidak menguntungkan secara ekonomis, karena penerimaan lebih kecil dari pada biaya total yang dikeluarkan.

Analisis biaya pemesanan bahan baku menurut kebijakan perusahaan dapat meliputi jumlah dan frekuensi produksi bahanbaku serta biaya persediaan bahan baku. Biaya persediaan yang dikeluarkan perusahaan dapat diketahui dari informasi yang diperoleh langsung dari Nabila Farm. Analisis metode Economic Order Quantity (EOQ) digunakan untuk mengetahui kuantitas pembelian bahan baku rockwool yang ekonomis (setiap kali pesan). Kuantitas pembelian bahan baku rockwool yang ekonomis didapatkan dari biaya pemesanan tahunan dan biaya penyimpanan tahunan.

a. Biaya pemesanan per tahun

Merupakan biaya-biaya yang dikeluarkan sehubungan dengan kegiatan pemesanan bahan baku. Biaya pemesanan berubah sesuai dengan frekuensi pemesanan.

$=$ jumlah pemesanan rockwool yang dilakukan per tahun $\mathrm{x}$ biaya pemesanan rockwool setiap kali pesan

$=\left(\frac{D}{Q}\right) \times S$

Keterangan:

$\mathrm{Q}=$ Jumlah barang setiap pemesanan

$\mathrm{D}=$ Kebutuhan rockwool tahunan

$\mathrm{S}=$ Biaya pemesanan untuk setiap pesanan

b. Biaya penyimpanan

Biaya penyimpanan adalah biaya yang ditanggung oleh perusahaan sehubungan dengan adanya bahan baku yang disimpan di dalam perusahaan, biaya simpan berfluktu-asi sesuai dengan tingkat persediaan. Semakin banyak barang yang disimpan, maka semakin besar barang persediaan dan semakin besar pula biaya penyimpannya.

Beberapa contoh biaya penyimpanan antara lain:

1) Biaya simpan bahan

2) Biaya peralatan simpan bahan

3) Biaya kerusakan bahan

4) Biaya tenaga kerja gudang

Adapun rumus biaya penyimpanan adalah sebagai berikut:

Biaya penyimpanan $=\left(\frac{Q}{2}\right) \times H$ 
Keterangan:

$\mathrm{H}=$ Biaya penyimpanan perunit

$\mathrm{Q}=$ Jumlah barang setiap pesanan

c. Metoode EOQ (Jumlah optimal rockwool per pemesanan)

Jumlah pesanan bahan baku optimal diperoleh saat biaya pemesananper tahun sama dengan biaya penyimpanan per tahun.

$\mathrm{Q}=\sqrt{\frac{2 D S}{H}}$

Keterangan:

$\mathrm{Q}=$ Jumlah rockwool setiap pemesanan

$\mathrm{D}=$ Kebutuhan rockwool tahunan

$\mathrm{S}=$ Biaya pemesanan rockwool tiap kali pesan

$\mathrm{H}=$ Biaya penyimpanan rockwool

d. Total biaya persediaan bahan baku (Total Inventory Cost)

Total persediaan bahan baku rockwool yang optimal ialah penjumlahan dari total biaya pesan dan total biaya simpan bahan baku rockwool. Q ialah jumlah optimal rockwool per pemesanan. $\mathrm{H}$ ialah biaya penyimpanan rockwool per tahun, dan $\mathrm{S}$ merupakan biaya pemesanan rockwool setiap kali pesan $(\mathrm{Rp})$.

TIC $=$ Total biaya pesan + Total biaya simpan

$$
T I C=\left(\frac{Q}{2} \times H\right)+\left(\frac{D}{Q}\right) \times S
$$

\section{HASIL DAN PEMBAHASAN}

\section{Analisis Biaya Produksi}

Dalam melakukan usaha diperlukannya kemauan dan kemampuan dalam bentuk nilai ekonomis yang biaya disebut biaya. Nabila Farm memerlukan biaya untuk melakukan budidayanya. Biaya produksi yang dikeluarkan terdiri atas biaya tetap dan biaya variabel. Rincian biaya produksi sayuran yang perlu dikerluarkan oleh Nabila Farm sebagai berikut:

1) Biaya Tetap

Biaya tetap adalah biaya yang pasti dikeluarkan oleh perusahaan dalam jumlah yang relatif sama pada setiap tahunnya untuk proses produksi. Biaya tetap terdiri atas biaya-biaya seperti biaya gaji karyawan, biaya peralatan produksi dan biaya penyusutan investasi. Biaya investasi yang dikeluarkan Nabila Farm adalah untuk pembangunan greenhouse dan peralatan produksi, peralatan semai dan peralatan pengemasan. 
Tabel 4. Komponen Biaya Investasi di Nabila Farm

\begin{tabular}{clrc}
\hline No & \multicolumn{1}{c}{ Komponen Biaya Investasi } & \multicolumn{1}{c}{ Nilai (Rp) } & Persentase (\%) \\
\hline 1. & Greenhouse 1 (GH1) & $239.250 .000,00$ & 89,9 \\
& Alat-alat kebutuhan greenhouse & $26.851 .500,00$ & 10,1 \\
& Total & $266.101 .500,00$ & 100 \\
\hline 2. & Greenhouse 2 (GH2) & $341.550 .000,00$ & 93,5 \\
& Alat-alat kebutuhan greenhouse & $23.591 .000,00$ & 6,5 \\
& Total & $365.141 .000,00$ & 100 \\
\hline 3. & Greenhouse 3 (GH3) & $721.050 .000,00$ & 93,2 \\
& Alat-alat kebutuhan greenhouse & $52.238 .000,00$ & 6,8 \\
Total & $773.288 .000,00$ & 100 \\
\hline 4. & $1.646 .500,00$ & 19,1 \\
& Alat-alat kebutuhan semai & $6.930 .000,00$ & 80,9 \\
& Total & $8.576 .500,00$ & 100 \\
\hline
\end{tabular}

Biaya pembangunan greenhouse adalah biaya yang dikeluarkan paling besar dari total biaya investasi. Biaya investasi greenhouse 3 (GH3) lebih besar pengeluarannya dibandingkan dengan greenhouse lainnya karena luasnya yang lebih besar pula. Biaya tetap yang dikeluarkan Nabila Farm terdiri atas biaya tenaga kerja dan biaya penyusutan investasi. Rincian komponen biaya tetap yang dijalani Nabila Farm tercantum pada Tabel 5.

Tabel 5. Komponen Biaya Tetap Nabila Farm

\begin{tabular}{lllc}
\hline No & Jenis Biaya Tetap & Jumlah (Rp) & \% \\
\hline 1. & $\begin{array}{l}\text { Penyusutan } \\
\text { Greenhouse 1 (GH1) }\end{array}$ & $29.295 .300,00$ & 19,2 \\
2. & $\begin{array}{l}\text { Penyusutan } \\
\text { Greenhouse 2 (GH2) }\end{array}$ & $38.873 .200,00$ & 25,5 \\
3. & $\begin{array}{l}\text { Penyusutan } \\
\text { Greenhouse 3 (GH3) } \\
\text { Penyusutan Alat-Alat } \\
\text { Semai }\end{array}$ & $82.552 .600,00$ & 54,1 \\
5enyusutan Alat-Alat & $1.386 .000,00$ & 0,9 \\
\hline & \multicolumn{1}{c}{ Pengemasan } & $152.436 .400,00$ & 100 \\
\hline
\end{tabular}

Biaya tetap yang dikeluarkan paling besar adalah biaya untuk penyusutan pada greenhouse 3 (GH3) dengan persentase $54 \%$ dari total biaya tetap yang dikeluarkan oleh Nabila Farm.

2) Biaya Variabel

Biaya variabel adalah biaya-biaya yang dikeluarkan dengan jumlah yang dapat berbeda-beda mengikuti perubahan kuantitas yang dibutuhkan. Biaya variabel dalam kegiatan produksi caisim di Nabila Farm terdiri atas biaya pembelian benih, biaya rockwool, biaya nutrisi, biaya pupuk, biaya listrik, biaya internet dan biaya bensin. Rincian biaya variabel yang dikeluarkan Nabila Farm dapat dilihat pada Tabel 6 .

Biaya variabel yang dikeluarkan paling besar ialah untuk tenaga kerja sebesar $49,8 \%$ dari total biaya pengeluaran variabel namun untuk kebutuhan bahan baku rockwool merupakan biaya yang dikeluarkan paling besar yaitu $12 \%$. 
Tabel 6. Komponen Biaya Variabel Dalam Satu Bulan

\begin{tabular}{llrc}
\hline No. & \multicolumn{1}{c}{$\begin{array}{c}\text { Jenis Biaya } \\
\text { Variabel }\end{array}$} & Jumlah (Rp) & \% \\
\hline 1. & Benih kale & $2.700 .000,00$ & 10,3 \\
2. & Benih kangkung & $1.430 .000,00$ & 5,4 \\
3. & Benih bayam merah & $245.000,00$ & 0,9 \\
4. & Benih bayam hijau & $245.000,00$ & 0,9 \\
5. & Benih caisim & $250.000,00$ & 0,95 \\
6. & Benih pakcoy & $250.000,00$ & 0,95 \\
7. & Benih pakcoy putih & $125.000,00$ & 0,47 \\
8. & Benih petsai & $125.000,00$ & 0,47 \\
9. & Pupuk atau Obat- & $350.000,00$ & 1,33 \\
& obatan & & \\
10. & Rockwool & $3.000 .000,00$ & 12 \\
11. & Biaya pengiriman & $200.000,00$ & 0,95 \\
& rockwool & & \\
12. & Nutrisi & $1.500 .000,00$ & 5,7 \\
13. & Listrik & $2.000 .000,00$ & 7,6 \\
14. & Internet & $350.000,00$ & 1,3 \\
15. & Bensin motor & $55.000,00$ & 0,41 \\
16. & Bensin viar & $150.000,00$ & 0,57 \\
17. & Gaji tenaga kerja & $13.000 .000,00$ & 49,8 \\
\hline & Total & $\mathbf{2 5 . 9 7 5 . 0 0 0 , 0 0}$ & $\mathbf{1 0 0}$ \\
\hline
\end{tabular}

\section{Analisis Usahatani Nabila Farm}

Untuk menganalisis usahatani dibutuhkan perhitungan total biaya, penerimaan dan keuntungan.

1. Total Biaya

Total biaya adalah jumlah dari keseluruhan biaya yang dikeluarkan selama proses produksi. Total biaya didapat dari penjumlahan biaya tetap dan biaya variabel.

$$
\begin{aligned}
& \mathrm{TC}=\mathrm{FC}+\mathrm{VC} \\
& \mathrm{TC}=\mathrm{Rp} 152.436 .400+\mathrm{Rp} 25.975 .000 \\
& \mathrm{TC}=\mathrm{Rp} 178.411 .400
\end{aligned}
$$

Total biaya produksi yang dikeluarkan oleh Nabila Farm ialah sebesar Rp 178.411.400,00. Persentase dari biaya tetap dan biaya variabel terhadap biaya produksi masing-masing adalah sebesar $85,3 \%$ dan $14,7 \%$.

\section{Penerimaan Usahatani}

Penerimaan adalah sejumlah uang yang diterima oleh perusahaan dari hasil penjualan produknya. Perhitungan penerimaan ini dari perkalian jumlah produksi dari harga jual produk. Penjualan produk ini dihitung dalam satuan pack (Tabel 7).

\begin{tabular}{|c|c|c|c|c|}
\hline No & Komoditas & $\begin{array}{c}\text { Jumlah } \\
\text { Produksi } \\
\text { (Pack) }\end{array}$ & $\begin{array}{l}\text { Harga } \\
\text { Jual } \\
\text { (Rp) }\end{array}$ & $\begin{array}{c}\text { Total } \\
\text { Penerimaan } \\
(\mathrm{Rp}) \\
\end{array}$ \\
\hline 1. & Bayam Hijau & 5.509 & 5350 & 29.473 .150 \\
\hline 2. & Bayam Merah & 3.833 & 5350 & 20.506 .550 \\
\hline 3. & Caisim & 15.646 & 5350 & 83.706 .100 \\
\hline 4. & Kailan & 6.914 & 5350 & 36.989 .900 \\
\hline 5. & Kangkung & 11.202 & 5350 & 59.930 .700 \\
\hline 6. & Pakcoy & 11.347 & 5350 & 60.706 .450 \\
\hline 7. & Pakcoy Putih & 4.455 & 5350 & 23.834 .250 \\
\hline 8. & Kale & 8.059 & 5500 & 44.324 .500 \\
\hline 9. & Petsai & 4.302 & 5350 & 23.015 .700 \\
\hline 10. & Baby Kale & 15.973 & 6450 & 103.025 .850 \\
\hline & Total & 87.240 & & 485.513 .150 \\
\hline
\end{tabular}

Tabel 7. Hasil Penerimaan Nabila Farm Periode November 2018 - Oktober 2019

Nabila Farm memiliki komoditas yang bermacam-macam dan harga jual setiap komoditas ada yang berbeda. Komoditas yang memiliki harga jual paling tinggi adaalah komoditas baby kale ialah sebesar Rp 6.450,00. Dari perkalian hasil produksi dan harga jual didapatkanlah penerimaan yang diperoleh Nabila Farm pada periode November 2018 - Oktober 2019 ialah sebesar Rp $485.513 .150,00$. 


\section{Keuntungan Produksi}

Keuntungan adalah hasil bersih yang diterima oleh perusahaan dari keseluruhan penerimaan setelah dikenai pajak. Pajak yang harus dikeluarkan oleh perusahaan mengikuti ketentuan mengenai Pajak Penghasilan No. 36 tahun 2008 Pasal 17, yaitu sebesar 25\% dari laba. Pajak yang harus dibayarkan oleh Nabila Farm ialah:

Net Benefit $=(\mathrm{TR}-\mathrm{TC}) \times$ Pajak

$=(\operatorname{Rp} 485.513 .150,00-\operatorname{Rp} 178.411 .400,00) \mathrm{x}$ $25 \%$

$=(\operatorname{Rp} 307.301 .750,00) \times 25 \%$

$=\operatorname{Rp} 76.775 .437,00$.

Keuntungan yang diperoleh oleh Nabila Farm ialah:

Net Benefit $=(\mathrm{TR}-\mathrm{TC})$ - Pajak

$=(\operatorname{Rp} 307.101 .750,00-\operatorname{Rp} 76.775 .437,50)$

$=\operatorname{Rp} 230.326 .312,50$

Keuntungan yang diperoleh Nabila Farm setelah dikenai pajak ialah sebesar Rp 230.326.312,50.

\section{Return Cost of Ratio (RCR)}

Return Cost of Ratio (RCR) adalah analisis yang digunakan untuk mengetahui efisiensi usahatani. Menurut Hernanto (1991), ada rumus yang digunakan untuk menghitung RCR yaitu:

$\mathrm{RCR}=\frac{\mathrm{Rp} 485.513 .150,00}{R p 178.411 .400,00}$

$\mathrm{RCR}=2,72$

Berdasarkan nilai tersebut, maka usahatani yang dijalankan Nabila Farm menguntungkan secara ekonomis karena $\mathrm{RCR}>1$

\section{Analisis Persediaan Bahan Baku}

\section{Menurut Kebijakan Perusahaan}

Nabila Farm merupakan usahatani hidroponik yang memerlukan bahan baku seperti benih, nutrisi, pupuk atau obatobatan dan rockwool. Bahan baku yang diperlukan cukup banyak adalah rockwool.

\section{Kebutuhan Rockwool}

Nabila Farm memperoleh bahan baku dari supplier, tetapi perusahaan yang menetapkan kualitas yang baik supaya tidak terjadi kerusakan saat proses produksi. Rockwool yang berisikan 10 lembar dalam 1 bal. Untuk dapat mengetahui kuantitas pemesanan bahan baku yang optimal dalam penyediaan bahan baku perlu mengetahui jumlah kebutuhan bahan baku rockwool setiap bulannya.

Rockwool untuk penyemaian dalam periode November 2018 - Oktober 2019 sebanyak 1.455 lembar rockwool dengan sejumlah 146 bal. Penggunaan rockwool tertinggi terjadi pada bulan Mei 2019 sebanyak 156 lembar rockwool. Selain itu jumlah pemesanan per pemesanan rockwool adalah 5 bal atau 50 lembar. Frekuensi pemesanan per bulannya adalah 2 kali sehingga dalam setahun perusahaan 
memesan rockwool sebanyak 24 kali.

Frekuensi pemesanan rockwool menurut kebijakan Nabila Farm terjadi 24 kali karena tidak adanya perhitungan untuk kebutuhan rockwool. Perusahaan melakukan pemesanan apabila rockwool sudah mulai habis.

1) Biaya Pemesanan dan Biaya Penyimpanan

Pengadaan bahan baku ini tidak akan terlepas dari biaya produksi. Untuk memenuhi kebutuhan bahan baku ini harus mengeluarkan biaya-biaya yang meliputi biaya pemesanan dan biaya penyimpanan. Besarnya biaya persediaan bahan baku bergantung pada frekuensi pemesanan bahan baku dan kuantitas bahan baku. Biaya persediaan yang harus diperhatian oleh Nabila Farm:

a) Biaya Pemesanan

Biaya pemesanan yang dikeluarkan adalah biaya-biaya yang berhubungan dengan pemesanan, meliputi:

\section{1) Biaya Kirim}

Biaya kirim adalah biaya yang timbul karena adanya jarak tempuh yang harus dilalui supplier kepada Nabila Farm. Biaya ini ada pada saat Nabila Farm melakukan pemesanan, setiap pemesanan biaya yang dikeluarkan sebesar $\mathrm{Rp}$. 100.000,00. Dalam sebulan Nabila Farm melakukan pemesanan rockwool sebanyak
2 kali sehingga biaya kirim yang dikeluarkan sebesar Rp. 200.000,00. Total biaya kirim per tahun: Rp. $200.000,00 \times 12=$ Rp. $2.400 .000,00$.

2) Biaya Internet

Biaya Internet sebagai biaya pemesanan karena setiap pemesanan berkomunikasi melalui Whatapp. Biaya yang dikeluarkan dalam sebulan adalah sebesar Rp. 350.000,00.

Total biaya internet per tahun:

Rp. $350.000,00 \times 12=$ Rp. $4.200 .000,00$.

Tabel 8. Total Biaya Pemesanan Periode November 2018 - Oktober 2019

\begin{tabular}{lc}
\hline Jenis Biaya & Jumlah (Rp) \\
\hline Biaya kirim & 2.400 .000 \\
Biaya internet & 4.200 .000 \\
\hline Total Biaya & $\mathbf{6 . 6 0 0 . 0 0 0}$ \\
\hline
\end{tabular}

b) Biaya Penyimpanan

Biaya penyimpanan adalah biayabiaya yang dikeluarkan yang berkaitan dengan penyimpanan persediaan. Biayabiaya tersebut adalah:

1) Biaya Tenaga Kerja

Biaya ini ada untuk membiayai tenaga kerja yang menata dan mengangkut bahan baku yang akan digunakan. Biaya tenaga kerja ini timbul pada saat adanya pemesanan bahan baku. Jumlah tenaga kerja yang bersangkutan ada 3 orang dan setiap tenaga kerja mendapatkan gaji $\mathrm{Rp}$ 40.000/bulan. Tenaga kerja ini termasuk dari tenaga kerja harian namun 3 orang 
tenaga kerja untuk rockwool mendapatkan tambahan upah karena bertanggung jawab untuk rockwool. Jadi biaya tenaga kerjanya adalah:

Rp 40.000,00 × $3=\operatorname{Rp~120.000,00.~}$

Rp. $120.000,00 \times 12=$ Rp. $1.440 .000,00$.

c) Total Biaya Persediaan Bahan Baku

Rockwool

Pengadaan bahan baku untuk kegiatan produksi tidak akan terlepas dari biaya produksi. Begitu juga dengan Nabila Farm harus mengetahui total biaya yang dikeluarkan untuk persediaan. Total biaya persediaan pada Nabila Farm mengeluarkan Rp 8.040.000,00 untuk persediaan rockwool. Hasil total biaya persediaan ini penjumlahan antara biaya pemesanan dan biaya penyimpanan.

\section{Analisis Persediaan Bahan Baku Dengan Metode Economic Order Quantity (EOQ)}

Untuk mengetahui pembelian bahan baku yang optimal dengan menggunakan metode EOQ di Nabila Farm membutuhkan data persediaan bahan baku rockwool yang dimiliki oleh Nabila Farm. Metode EOQ yaitu suatu metode yang menentukan jumlah kebutuhan bahan baku yang optimal dengan biaya yang minimum.

1. Pemesanan Bahan Baku Rockwool yang Optimal
Data yang digunakan antara lain jumlah bahan baku rockwool yang dibutuhkan selama satu tahun (D), biaya pemesanan setiap kali pesan (S), dan biaya penyimpanan per tahun $(\mathrm{H})$.

a. Biaya pesan tiap kali pesan

$$
\begin{aligned}
\text { S } & =\frac{\text { Total Biaya Pemesanan }}{\text { Frekuensi Pemesanan }} \\
& =\frac{\text { Rp } 6.600 .000}{24} \\
& =\text { Rp. } 275.000,00,-
\end{aligned}
$$

b. Biaya penyimpanan per tahun

$$
\begin{aligned}
& \mathrm{H}=\frac{\text { Total Biaya Penyimpanan }}{\text { Jumlah Kebutuhan }} \\
& =\frac{\text { Rp. } 1.440 .000}{146}
\end{aligned}
$$$$
=\text { Rp. 9.863,00. }
$$

Telah diketahui bahwa jumlah penggunaan bahan baku rockwool untuk caisim pada periode November 2018 Oktober 2019 yaitu 202 lembar rockwool atau 146 bal. Biaya pemesanan setiap kali pesan sebesar Rp 275.000,00, sedangkan biaya penyimpanan per tahunnya sebesar Rp 9.863,00.

Dari hasil perhitungan diketahui jumlah pemesanan optimal bahan baku rockwool tiap kali pesan sebagai berikut:

$$
\begin{aligned}
& E O Q=\sqrt{\frac{2 S D}{H}} \\
& E O Q=\sqrt{\frac{2 \times 275.000 \times 146}{9.863}} \\
& E O Q=90,2 \approx 90 \mathrm{bal}
\end{aligned}
$$


Jumlah pemesanan rockwool yang optimal adalah 90 bal dengan frekuensi pemesanan 2 kali.

2. Total Biaya Persediaan

Telah diketahui total kebutuhan bahan baku rockwool pada periode November 2018 - Oktober 2019 dalam bal (D) sebanyak 146 bal. Jumlah barang setiap pemesanan (Q) sebanyak 20 bal. Biaya pemesanan untuk setiap kali pesan (S) sebesar Rp. 275.000,00 dan Biaya penyimpanan per tahun (H) Rp. 9.863,00.

Maka total biaya persediaan (TIC) adalah:

$\mathrm{TIC}=\frac{D}{Q} x S+\frac{Q}{2} x H$

$\mathrm{TIC}=\frac{146}{90} \times 275.000+\frac{90}{2} \times 9.863$

$\mathrm{TIC}=446.111,11+443.835$

$\mathrm{TIC}=R p 889.946,11$

Total biaya persediaan bahan baku rockwool yang optimal ialah $\mathrm{Rp}$ $889.946,11$.

Setelah mengetahui jumlah pemesanan bahan baku yang optimal dan besarnya biaya-biaya yang harus dikeluarkan dalam pengadaan bahan baku, maka perlu dilakukan pembandingan antara perhitungan persediaan bahan baku menurut kebijakan perusahaan dengan perhituangan persediaan bahan baku menurut metode Economic Order Quantity (EOQ). Hal ini ditujukan untuk mengetahui jumlah biaya yang dikeluarkan untuk persediaan bahan baku. Hasil analisis persediaan menurut perusahaan dan menurut metode Economic Order Quantity (EOQ) tersaji pada Tabel 9.

Tabel 9. Hasil Analisis Persediaan Bahan Baku Rockwool

\begin{tabular}{lccc}
\hline $\begin{array}{c}\text { Pesediaan } \\
\text { Bahan Baku }\end{array}$ & $\begin{array}{c}\text { Jumlah } \\
\text { Pemesanan } \\
\text { (Bal) }\end{array}$ & $\begin{array}{c}\text { Frekuensi } \\
\text { Pemesanan }\end{array}$ & $\begin{array}{c}\text { Total Biaya } \\
\text { Persediaan } \\
\text { (Rp) }\end{array}$ \\
\hline $\begin{array}{l}\text { Kebijakan } \\
\text { Perusahaan }\end{array}$ & 5 & 24 & $8.040 .000,00$ \\
\hline $\begin{array}{l}\text { Metode } \\
\text { EOQ }\end{array}$ & 90 & 2 & $889.946,11$ \\
\hline
\end{tabular}

Hasil dari analisis persediaan ini didapatkan untuk pemesanan yang optimal sebesar 90 bal dengan frekuensi 2 kali pemesanan. Selisih yang di dapat dengan metode Economic Order Quantity (EOQ) dan kebijakan perusahaan sebesar $\mathrm{Rp}$ 7.150.053,89. Frekuensi pemesanan rockwool menurut kebijakan Nabila Farm terjadi 24 kali karena tidak adanya perhitungan untuk kebutuhan rockwool. Lokasi ruang penyimpanan rockwool bersebelahan dengan ruang gelap, kapasitas untuk ruang penyimpanan rockwool cukup luas untuk menyimpan rockwool hingga 90 bal.

Pemesanan dengan metode Economic Order Quantity (EOQ) lebih besar dibandingkan dengan kebijakan perusahaan karena untuk meminimalisir total biaya persediaan, maka pembeliaan bahan baku rockwool dilakukan dalam 
jumlah yang besar dan dengan frekuensi pembelian yang lebih rendah. Jenis persediaan menurut metode termasuk pada jenis Lot Size Inventory, dimana perusahaan mengumpulkan persediaan bahan baku supaya dapat berproduksi menggunakan seluruh bahan baku rockwool ini dalam jumlah yang cukup dengan tujuan dapat mengurangi biaya persediaan.

Metode Economic Order Quantity (EOQ) dapat meminimalkan biaya yang dikeluarkan oleh perusahaan. Setelah melihat hasil perhitungan dan selisihnya apabila perusahaan menggunakan metode Economic Order Quantity (EOQ), maka biaya yang dikeluarkan akan lebih sedikit dan dapat menghemat pengeluaran terutama dari biaya persediaan.

\section{KESIMPULAN DAN SARAN}

\section{Kesimpulan}

1. Biaya produksi yang dikeluarkan oleh Nabila Farm ialah sebesar Rp 178.411.400,00 dengan biaya tetap dan biaya variabelnya sebesar $\mathrm{Rp}$ 152.436.400,00 dan Rp 25.975.000,00. Persentase untuk biaya tetap dan biaya variabel ialah sebesar $85,3 \%$ dan $14,7 \%$. Hasil penjualan yang diterima oleh Nabila Farm sebesar Rp 485.513.150,00 dan keuntungan setelah dikenai pajak sebesar Rp 230.326.312,50. Return Cost of Ratio (RCR) yang diperoleh Nabila Farm adalah $\mathrm{RCR}>1$, maka usahatani ini menguntungkan secara ekonomis.

2. Pembeliaan bahan baku rockwool yang optimal menurut metode Economic Order Quantity selama periode November 2018-Oktoboer 2019 di Nabila Farm untuk setiap kali pesan lebih besar dari pada kebijakan perusahaan. Pembelian bahan baku menurut kebijakan perusahaan sebanyak 5 bal, setelah perhitungan menurut metode Economic Order Quantity didapat jumlah optimal sebanyak 90 bal. Frekuensi pemesanan menurut kebijakan perusahaan dilakukan sebanyak 24 kali sedangkan menurut metode Economic Order Quantity sebanyak 2 kali.

3. Total biaya persediaan bahan baku rockwool yang telah dikeluarkan Nabila Farm pada periode November 2018-Oktober 2019 sebesar Rp 8.040.000,00 sedangkan menurut perhitungan metode Economic Order Quantity lebih kecil yaitu sebesar Rp $889.946,11$. Hal ini menunjukan bahwa dengan metode Economic Order Quantity dapat menekan biaya yang 
dikeluarkan perusahaan untuk persediaan bahan baku rockwool.

\section{Saran}

Dalam pengadaan bahan baku rockwool, Nabila Farm sebaiknya menerapkan metode Economic Order Quantity (EOQ) yaitu melakukan pembeliaan yang banyak dengan frekuensi yang rendah dapat meminimalisir biaya persediaan. Diharapkan metode Economic Order Quantity (EOQ) dapat diterapkan untuk kebutuhan bahan baku lainnya.

\section{DAFTAR PUSTAKA}

BPS. (2018). Statistik Pertanian Indonesia. BPS. Jakarta.

BPS. (2018). Kabupaten Bandung Barat Dalam Angka. BPS, Jakarta.

BPS. (2018). Statistik Tanaman Sayuran dan Buah-buahan Semusim Indonesia. BPS. Jakarta
Creswell, J. (2002). Research Design : Desain Penelitian. Jakarta: KIK Press

Herwibowo, Kunto dan N.S. Budiana. (2015). Hidroponik Portabel. Jakarta: Penebar Swadaya

Hussain. (2004). Manajemen Bisnis Terhadap Penerimaan Produksi. Jakarta : PT. Gramedia Pustaka Utama.

Martawijaya EI, Nurjayadi MY. (2010). Bisnis Jamur Tiram di Rumah Sendiri. Bogor (ID): IPB Press.

Murtiningsih, Sri. 2004. http://digilib.uns.ac.id. Optimalisasi Persediaan Bahan Baku Biji Plastik Murni Untuk Kelancaran Proses Produksi Pada Perusahaan Plastik Bintang Fajar di Sukoharjo. Diakses pada tanggal17 April 2009.

Sonneveld.C. (1991). Rockwool as a Substrate for Greenhouse Crops. Biotechnology in Agriculture and Forestry, Vol. 17, pp. 285-312.

Sukirno, S. (2000). Makro Ekonomi Modern. Jakarta: PT. Raja Grafindo Perkasa. 